\title{
The basophil activation test by flow cytometry: recent developments in clinical studies, standardization and emerging perspectives Radhia Boumiza ${ }^{1}$, Anne-Lise Debard ${ }^{1}$ and Guillaume Monneret*1,2
}

\author{
Address: ${ }^{1}$ Immunology Laboratory, Lyon-Sud University Hospital, Lyon, France and ${ }^{2}$ Immunology Laboratory, Hôpital Neurologique, Lyon, \\ France \\ Email: Radhia Boumiza - radhiaboumiza@yahoo.com; Anne-Lise Debard - anne-lise.debard@chu-lyon.fr; \\ Guillaume Monneret* - guillaume.monneret@chu-lyon.fr \\ * Corresponding author
}

Published: 30 June 2005

Clinical and Molecular Allergy 2005, 3:9 doi:10.1186/1476-7961-3-9
Received: 04 May 2005

Accepted: 30 June 2005

This article is available from: http://www.clinicalmolecularallergy.com/content/3/1/9

(c) 2005 Boumiza et al; licensee BioMed Central Ltd.

This is an Open Access article distributed under the terms of the Creative Commons Attribution License (http://creativecommons.org/licenses/by/2.0), which permits unrestricted use, distribution, and reproduction in any medium, provided the original work is properly cited.

\begin{abstract}
The diagnosis of immediate allergy is mainly based upon an evocative clinical history, positive skin tests (gold standard) and, if available, detection of specific lgE. In some complicated cases, functional in vitro tests are necessary. The general concept of those tests is to mimic in vitro the contact between allergens and circulating basophils. The first approach to basophil functional responses was the histamine release test but this has remained controversial due to insufficient sensitivity and specificity. During recent years an increasing number of studies have demonstrated that flow cytometry is a reliable tool for monitoring basophil activation upon allergen challenge by detecting surface expression of degranulation/activation markers (CD63 or CD203c). This article reviews the recent improvements to the basophil activation test made possible by flow cytometry, focusing on the use of anti-CRTH2/DP 2 antibodies for basophil recognition. On the basis of a new triple staining protocol, the basophil activation test has become a standardized tool for in vitro diagnosis of immediate allergy. It is also suitable for pharmacological studies on non-purified human basophils. Multicenter studies are now required for its clinical assessment in large patient populations and to define the cut-off values for clinical decision-making.
\end{abstract}

\section{Introduction}

Anaphylaxis consists of an immediate IgE-dependent reaction in response to allergens. Clinical symptoms are caused by an initial systemic histamine release by mast cells and basophils that may lead to shock with laryngeal edema, lower-airway obstruction and hypotension. The most frequent allergens involved in immediate allergy are found in peanuts, fish, bee and wasp venoms, drugs and latex $[1,2]$. The identification of responsible allergens remains a key step for practicing allergen avoidance and specific immunotherapy. The diagnosis is mainly based upon an evocative clinical history (including temporal association between symptoms and allergen exposure), positive skin tests, which remain the gold standard in this context and, if available, detection of specific IgE [3]. In most patients, these features allow both diagnosis and identification of the offending allergen. Nevertheless, skin testing is contraindicated in some patients with histories 
of life-threatening anaphylaxis, and discrepant results may be found between clinical assessment of the disease and biological results, especially for drug allergy. In these cases, functional in vitro tests are necessary. The general concept of those tests is to mimic in vitro the contact between allergens and the cells responsible for symptoms (i.e. . those possessing the ability to release histamine). Until recently, basophils were neglected and only considered to be circulating forms of mast cells of minor importance. Furthermore, basophils represent in peripheral blood less than 0.5 percent of total leukocytes, making their purification difficult in clinical laboratories. This lack of satisfactory in vitro protocols has clearly hampered research on basophils for many years [4]. Nevertheless, there is considerable recent evidence that basophils are clinically relevant. Indeed, they are now considered as equivalent to tissue mast cells cells since they play, by themselves, a pivotal role in the immediate allergic reaction [5-8]. Consequently, functional in vitro tests for allergic reactions are focused on circulating basophils. The first approach to basophil functional studies was the histamine release test. However, its clinical benefit has remained controversial due to insufficient sensitivity and specificity $[3,9,10]$. That is why several groups took advantage of flow cytometry to develop new tools for monitoring basophil activation upon allergen challenge by detecting surface expression of degranulation markers [11-13].

\section{Principle of basophil activation test by flow cytometry}

As flow cytometry is a valuable tool for the analysis of many different cell types and can be used to identify specific populations of cells, even when present in low numbers, it seemed to be suitable for the study of allergeninduced basophil degranulation. Identification of cells was initially based both on CD45 expression, a common leukocyte antigen, and on the presence of IgE on the cell surface, since basophils express the high affinity receptor for IgE (FcERI) [9,14]. In this gated population, cell activation upon allergen challenge was assessed by the expression of CD63 on the membrane $[15,16]$. CD63 is anchored in the basophilic granule membrane (which contains histamine) and its exposure to the outside of the cells reflects cell degranulation due to fusion between granules and plasma membranes (figure 1). Thus, CD63 expression has been proposed as a reliable means to monitor basophil activation [11-13]. Briefly, whole blood was incubated at $37^{\circ} \mathrm{C}$ with allergens for 15 minutes. The reaction was stopped on ice, followed by a 30-min staining with antibodies (figure 1). Finally, samples were lysed to eliminate red cells. Basophils expressing both CD45 and surface IgE were then examined for their CD63 expression. The threshold for positivity was determined with the use of a negative control (i.e., whole blood and vehicle without allergen). Results were considered positive when at least 2 sequential allergen dilutions induced greater than than $10 \%$ increases in CD63-positive basophils above control values. This kind of protocol has been validated for common allergens by several groups and has shown convincing results [17-24]. The technique has proven to be accessible, rapid (results in less than 1 hour) and requires small amount of blood $(<5 \mathrm{~mL}$, even for assessing several allergens in the same experiment). In our hands, in allergy to muscle relaxants, the results were quite interesting, since we found the sensitivity of the CD63 test was similar to that for specific IgE detection and higher than the one for histamine release test [25]. This confirmed the value of performing the CD63 test rather than histamine release, which is furthermore costly in terms of both reagents and laboratory technician time. In accord with previous studies focusing on different allergens [17-21], this method showed excellent specificity. However, with respect to drug allergy, the main indication for this kind of test, three independent studies reported similar sensitivities ranging between 50 and $64 \%$, which is not sufficient for clinical usefulness $[12,25,26]$. In fact, this first approach relied on two important characteristics of basophils which were problematic: recognition through the expression of IgE on their surface (which is known to be highly variable from one patient to another) and the monitoring of their activation by detecting CD63 (which is also expressed to some extent by other activated leukocytes and by activated platelets that may adhere to basophils). This may explain why, when applied to drug allergy, these tests have remained somewhat disappointing in terms of sensitivities $[12,25,26]$. Consequently, we concluded that an activation marker that is more specific and/or sensitive than CD63 would be desirable.

\section{CD203c as a specific marker of activated basophils}

CD203c corresponds to a surface antigen expressed on human basophils recently recognized by the monoclonal antibody 97A6 [27]. This antigen, belonging to the type II transmembrane protein family, is a multifunctional ectoenzyme called ectonucleotide pyrophosphatase phophodiesterase 3 (E-NPP3) [28] that catalyzes the cleavage of a number of molecules including deoxynucleotides and nucleotide sugars [29]. In addition, E-NPP3 contains a somatomedin B-like domain and a cell adhesive motif, but their potential functions remain totally unknown with respect to basophil physiology. Among leukocytes CD203c appears to be selectively expressed on the basophil/mastocytes lineage [27]. To date, no other cells from human peripheral blood have been reported to express this marker. Its expression on basophils is rapidly upregulated after stimulation with the appropriate allergen in patients sensitized to acarids or hymenoptera or after crosslinking of FcERI with anti-IgE antibodies $[28,30]$. This suggests that CD203c up-regulation is more or less specific to the crosslinking of FceRI (figure 2). 


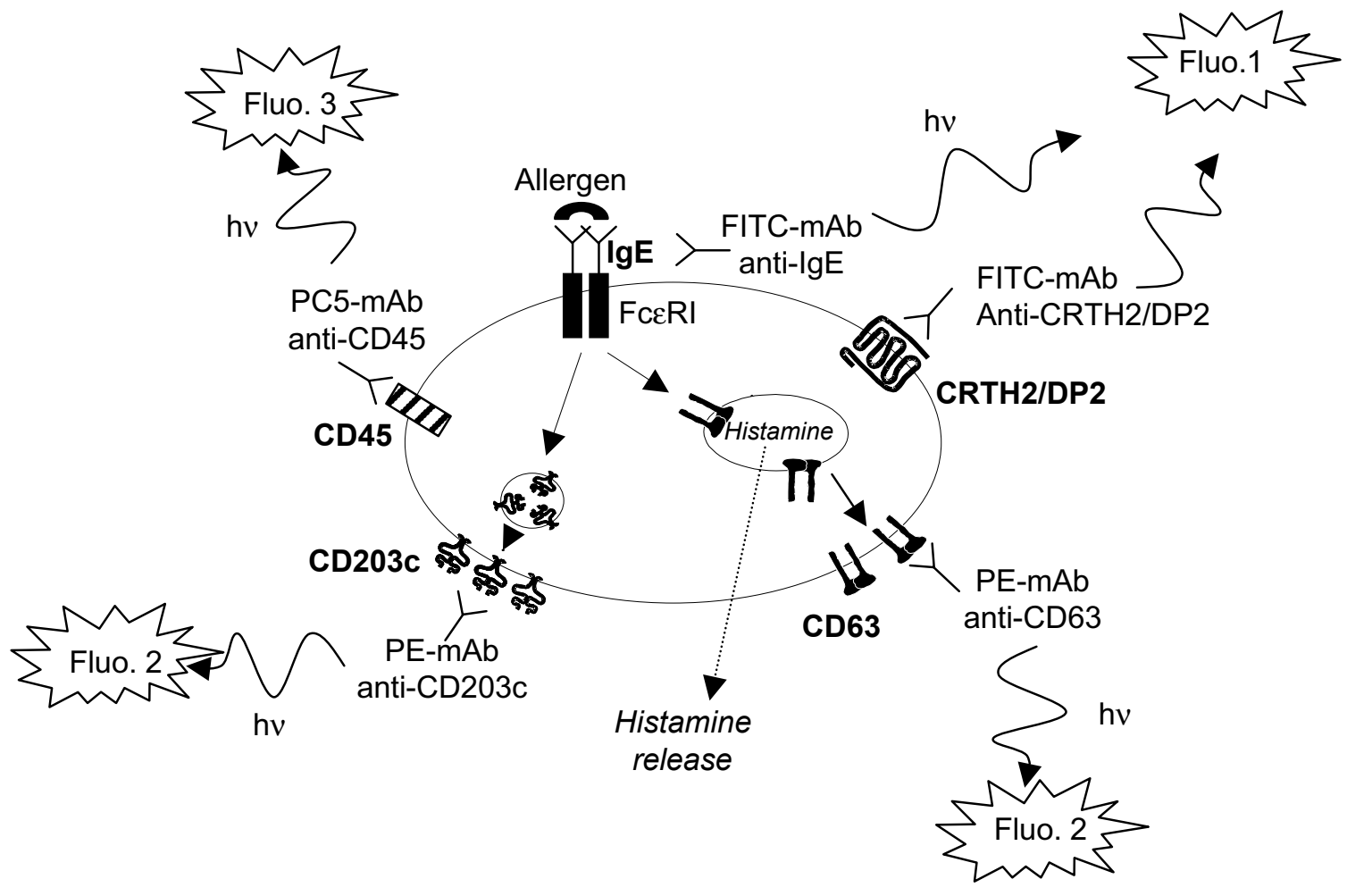

\section{Figure I}

Principle of the basophil activation test by flow cytometry (triple staining). Basophils are identified on the basis of CD45 expression (fluorescence 3 / Phyco-Cyanine 5) and the presence of IgE or CRTH2/DP2 on their surface (fluorescence I / Fluorescein isothiocyanate). Resting basophils do not express CD63 (anchored in the basophilic granule) and weakly express CD203c. The cross-linking of two FceRI (induced by an allergen or anti-lgE antibodies) provokes the histamine release (and as a consequence the CD63 expression) and the upregulation of CD203c. The rise in CD63 or CD203c expression (measured by fluorescence 2 / Phycoerythrin) before and after allergen challenge reflects thus the basophil activation / degranulation in response to an allergen.

Hence, as CD203c is rapidly upregulated after allergen challenge, it has been proposed as a new tool for allergy diagnosis [30-33]. We compared basophil activation tests using either CD63 or CD203c in the diagnosis of latex allergy [34] and found that the sensitivity was considerably higher with CD203c (75\% compared to 50\% with CD63). The improved sensitivity may be due to two factors. First, the recognition of basophils is better with CD203c. Indeed, the identification of basophils using prior protocols relied on a single IgE-labeling, although it is known that FceRI expression can vary considerably on cell surfaces from one patient to another [35]. This may explain why in some cases basophils were difficult or impossible to identify. The second reason for the improved sensitivity with CD203c is due to its higher expression in activated basophils compared to CD63 in our experiments. In sensitized patients, basophils increased their CD203c levels up to $350 \%$ above control values in response to allergens whereas the increase in CD63 was below $100 \%$. Similar results were obtained when expressing the results as the percentages of basophils that were CD203c- or CD63-positive. Even with the highest concentration of latex, the mean percentage of CD63-positive basophils was below $20 \%$ while that of 

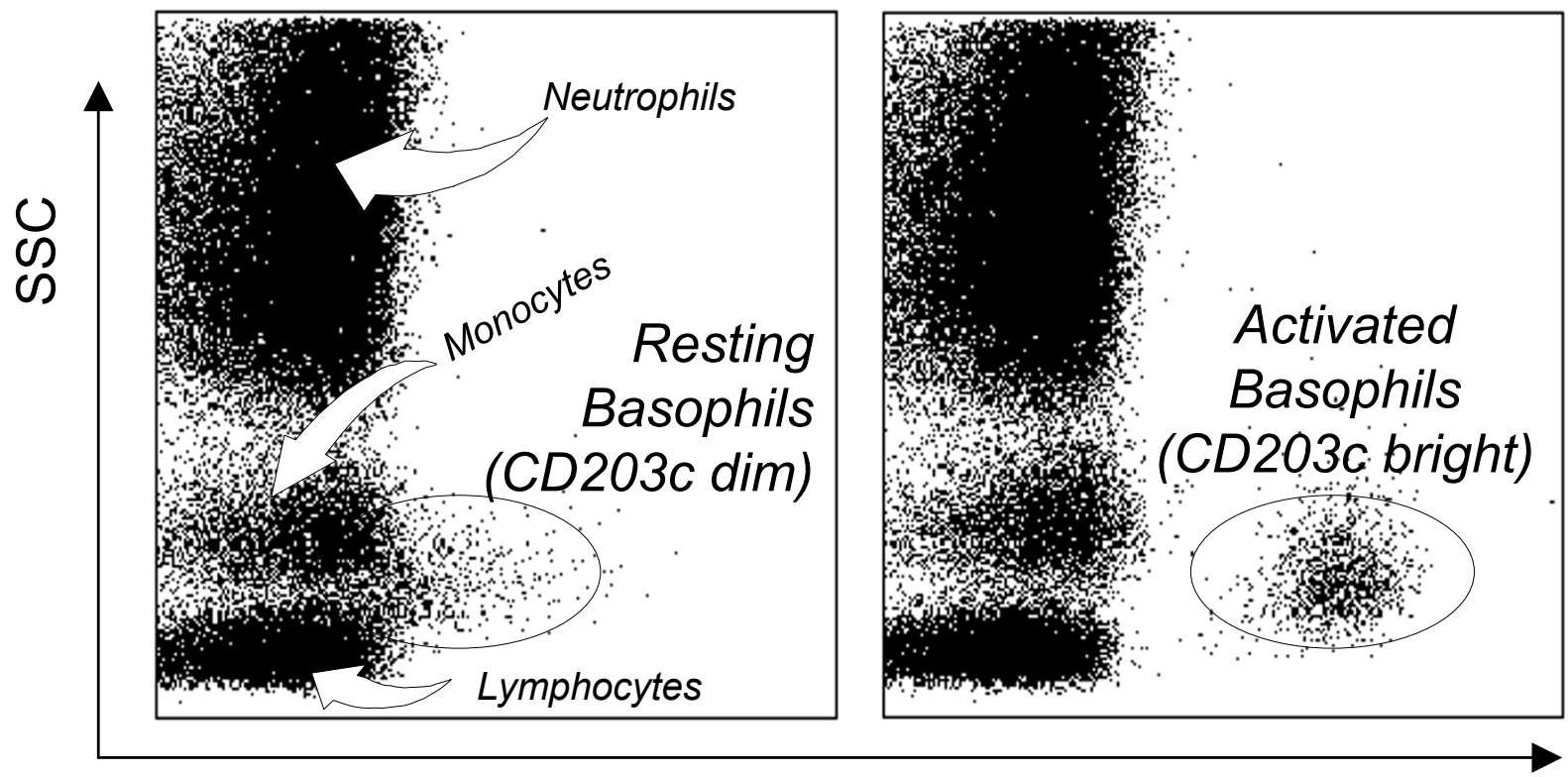

CD203c

\section{Figure 2}

CD203c expression in whole blood before and after basophil activation. Ungated leukocytes are shown as a biparametric representation on the basis of side scatter characteristics (SSC, $y$-axis) and CD203c (x-axis). Left histogram depicts resting cells, basophils express low levels of CD203c (some of them are not distinguishable from lymphocytes and monocytes). Right histogram depicts cells after anti-IgE challenge, activated basophils are easily recognized on the basis of their high CD203c expression.

CD203c-positive basophils was $48 \%$, allowing a clear distinction between resting and activated basophils [34]. In conclusion, both easier gating and higher range of activation in response to allergen may contribute to an improvement in the basophil activation test when using CD203c rather than CD63. However, as very few studies concomitantly compared CD203c and CD63, this point remains to be confirmed by additional works dealing with various allergens. Bühring and colleagues in a recent report proposed to use both markers in the same test to increase sensitivity [32]. It is supported by recent evidence showing that CD63 and CD203c overexpression depend on different stimulatory pathways [36,37]. It is to note that some novel basophil-activation markers (CD13, CD107a, CD164) have been very recently identified [37]. They have to be further investigated in clinical studies either by their own or in combination with CD63 or CD203c.

\section{CRTH2/DP 2 as a new marker for basophil recognition}

Finally, the last drawback of the previously described protocols remained the use of an anti-IgE reagent to identify basophils. Because of its selective expression on cells associated with Th2 responses (Th2 lymphocytes, eosinophils and basophils), CRTH2 (chemoattractant receptorhomologous molecule expressed on $\mathrm{Th} 2$ cells)/ $\mathrm{DP}_{2}$ has been proposed and validated as the most reliable tool for the detection of circulating human Th2 cells [38,39]. CRTH2 is also termed $\mathrm{DP}_{2}$ since it corresponds to the second receptor of prostaglandin $\mathrm{D}_{2}[40,41]$. As CRTH2 is highly expressed on basophils, we hypothesized that it could improve the basophil activation test by facilitating basophil recognition. Consequently, we developed a new three-colour flow cytometric protocol (PE-CD203c / FITC-CRTH2 / PC5-CD3) for monitoring allergeninduced basophil activation. First results were encouraging: CRTH2 staining allowed CRTH2-expressing cells 

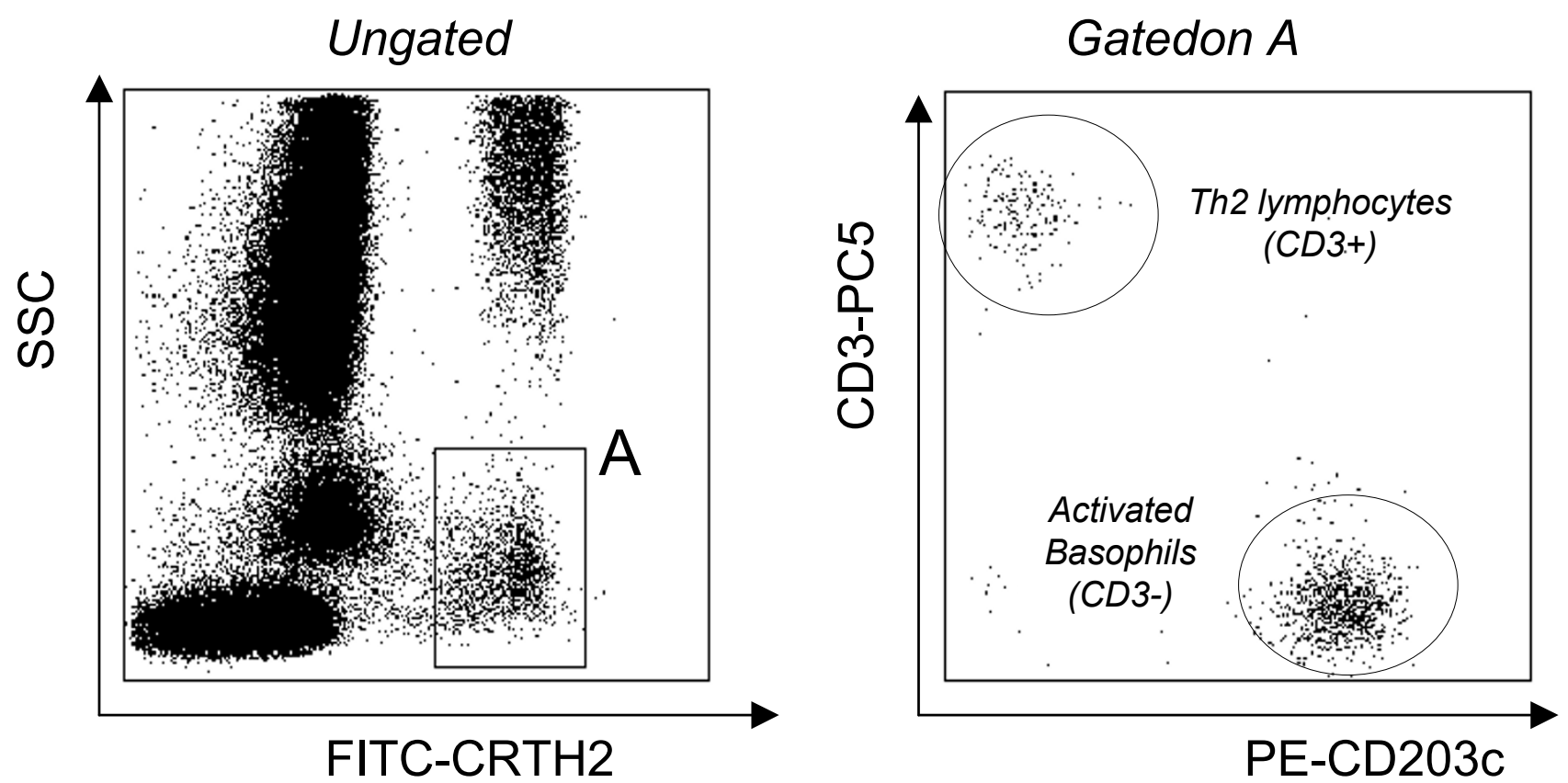

Figure 3

Identification of CRTH2 expressing cells by flow cytometry. Left histogram : ungated leukocytes biparametric representation on the basis of side scatter characteristics (SSC, $Y$ axis) and FITC-CRTH2 (X axis). Two CRTH2 expressing cell populations are easily distinguishable: the one with high light scatterings corresponds to the eosinophil population; the second one (gating region: $A$ ) comprises Th2 lymphocytes and basophils. Right histogram: cells from the gating region (A) expressed on the basis of PE-CD203c (X axis) and PC5-CD3 (Y axis) characteristics. Th2 lymphocytes were readily separated from basophils based on their positive CD3 expression while activated basophils express high levels of CD203c without expressing CD3.

(eosinophils, basophils and Th2 lymphocytes) to easily be distinguished from other cells in samples of whole blood (figure 3). On the basis of light scattering, eosinophils were easily excluded from the analysis (figure 3). Basophils could then readily be distinguished from Th2 lymphocytes on the basis of CD3, staining, as this marker is not present on basophils (figure 3). Finally, on this gated population of basophils (low light scatterings, CRTH2+ and CD3-), modulation of CD203c after allergen challenge was monitored as described in the former protocol (figure 4). To validate this protocol, 18 subjects were included in a preliminary study [42]. Patients were allergic to either latex (k82) or Dermatophagoïdes pteronyssinus (d1), had a suggestive clinical history, positive skin test and/or specific IgE $\geq$ class III. Healthy donors, from our laboratory, were not known to be allergic and presented total $\mathrm{IgE}<100 \mathrm{kU} / \mathrm{L}$. In terms of clinical interpretation, sensitivity and specificity were $88 \%$ and $100 \%$, respectively [40]. CRTH2 staining was an excellent means to identify basophils and we confirmed our earlier observations of a wide range of CD203c expression in response to allergen in tehse cells. In terms of basophil recovery, we compared our CRTH2-staining protocol with 2 others protocols using either anti-IgE or anti-CD123 (IL-3 receptor). In all patients and healthy individuals, we found more basophils (up to $50 \%$ in certain patients) with the CRTH2-staining protocol, illustrating its superiority with respect to basophil recovery. To conclude, the easy recognition of basophils and the reliable assessment of their activation make this protocol the most reliable tool for investigating basophil activation by flow cytometry. It may constitute a critical step for the interlab standardization of this kind of test. Lastly, since CRTH2 is also a marker of Th2 cells and eosinophils, it may become a promising tool for flow cytometry, providing a direct overview of cells involved in "Th2 diseases" such as allergy.

\section{Perspectives in pharmacological studies}

Until recently, due to the very low number of circulating basophils in humans, pharmacological studies on these cells were difficult to perform. This required large amount of blood and / or lengthy purification procedures that may induce nonspecific activation. By the use of flow 


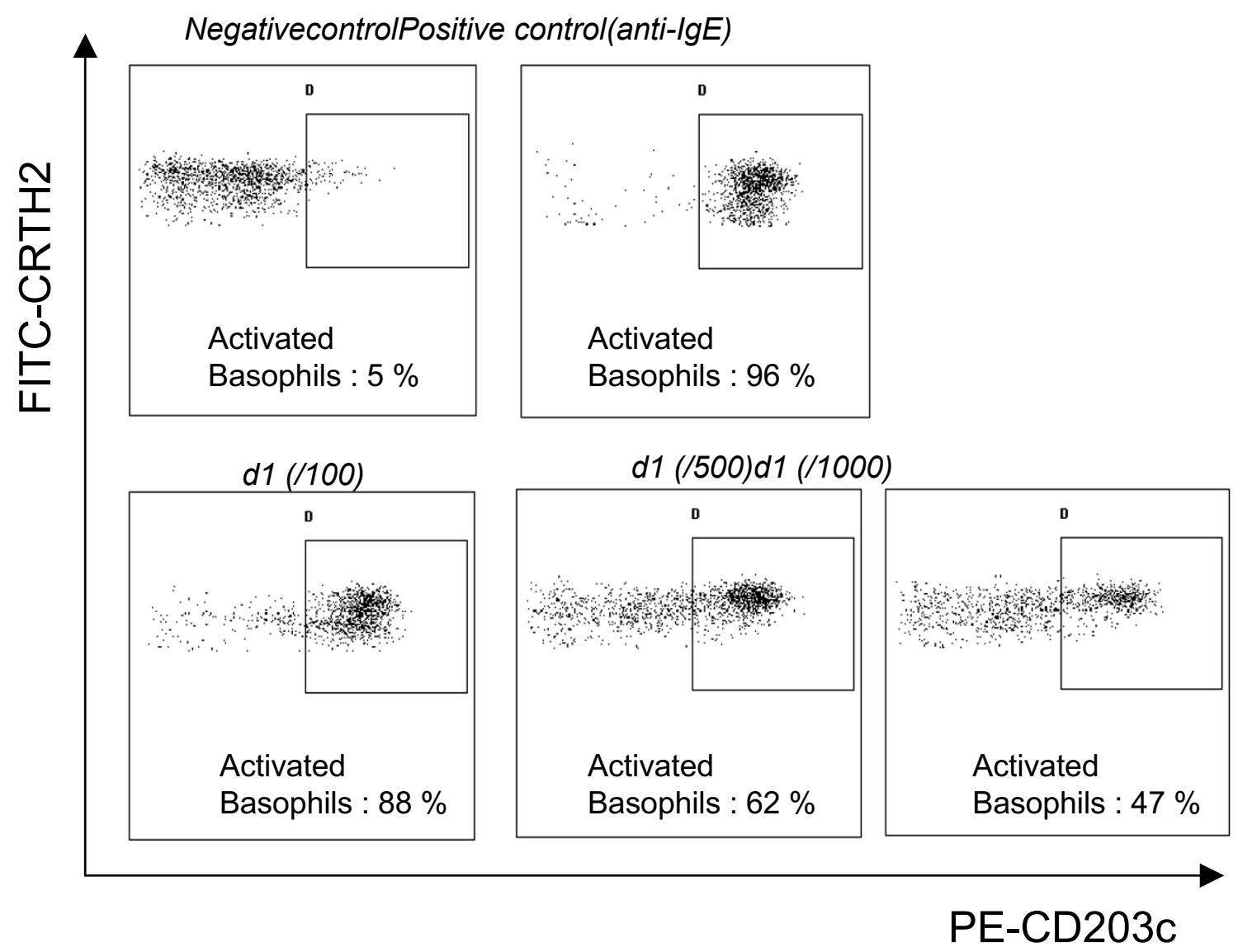

\section{Figure 4}

Representative increased expression of CD203c after allergen challenge in a patient allergic to Dermatophagoïdes pteronyssinus (d I). Gated CRTH2-positive basophils (after excluding Th2 lymphocytes as described in figure 3) are presented on the basis of CD203c-CRTH2 staining: before stimulation (negative control, upper left dot-plot), after antiIgE challenge (positive control, upper right) and after allergen challenge at 3 different concentrations (dose-effect response, lower dot-plots). Activated basophils: percentage of basophils expressing CD203c.

cytometry, the effects of different compounds on basophils may be examined in unfractionated human blood cells. Recently, we have been able to demonstrate that among various eicosanoids, prostaglandin $\mathrm{D}_{2}$ was by far the most potent activator of basophils, inducing CD203c and CD11b elevation [37]. This response was mediated by the DP2 receptor / CRTH2 as it was shared by selective agonists of this receptor. As previously observed in eosinophils [39], the interaction of prostaglandin $D_{2}$ with the $\mathrm{DP}_{1}$ receptor limited the activation of basophils by this prostaglandin. This suggested that the balance between $\mathrm{DP}_{1}$ and $\mathrm{DP}_{2}$ receptors may be crucial in determining the magnitude of basophil responses during allergic processes since prostaglandin D2 is known to be involved in allergic diseases and asthma. Using a similar approach, Heinemann et al. [43] examined the effects of various chemokines on human basophils and demon- 
strated a different pattern of chemokine receptor usage than those described for eosinophils and monocytes.

These studies illustrate that it is now possible to perform pharmacological and drug screening studies by flow cytometry. This approach could be very useful in assessing the possible risks of inducing anaphylactoid or pseudoanaphylactoid reactions when developing new molecules. To this end, one important task for the future will be to extend these kinds of protocols to animal models although, to our knowledge, there is no available information on CD203c in animals and monoclonal antibodies directed against human CD203c do not cross-react with other species [32].

\section{Conclusion}

After several improvements, the basophil activation test (using either CD203c or CD63 as activation marker) has become a robust and reliable test for in vitro investigations of immediate allergy, complementary to other existing in vitro tests. It is suitable for experimental and pharmacological studies as well as allergy diagnosis in clinical practice. There is now a crucial need for inter-laboratory standardization in clinical decision-making. Each allergen has to be assessed one by one to determine its optimal concentration (i.e., inducing maximal activation in vitro) as well as the definition of the threshold for positivity (using ROC analysis) since the use of an arbitrary cut-off value is likely not suitable for all allergens. The present challenge is to take advantage of the availability of improved methods to perform multicenter studies using a standardized protocol.

\section{Competing interests}

The author(s) declare that they have no competing interests.

\section{Authors' contributions}

$\mathrm{RB}$ participated as investigator and is the main author of the article.

\section{ALD participated in drafting the manuscript.}

GM was project leader and participated in the design of the different studies and drafting the manuscript.

\section{Acknowledgements}

We thank the technical staff of the flow cytometry unit - Immunology lab (J. Baudot, C. Fernandez, MA. Guinand, MC. Gutowski) at the Lyon-Sud University Hospital, Pr. J. Bienvenu (Immunology lab, Lyon-Sud University Hospital) for supporting our work on basophil activation over the years, G. Bouvier and C. Canino (Immunotech, Marseille, France) for kindly providing anti-CRTH2 antibodies.

\section{References}

I. Kay AB: Allergy and allergic diseases (part I). N Engl J Med 200I, 344:30-7.

2. Kay AB: Allergy and allergic diseases (part 2). $N$ Engl J Med 200I, 344:109-13.

3. Hamilton RG, Adkinson NF: In vitro assays for the diagnosis of IgE-mediated disorders. J Allergy Clin Immunol 2004, I | 4:2 I 3-225.

4. Falcone $\mathrm{FH}$, Haas H, Gibbs BF: The human basophil: a new appreciation of its role in immune responses. Blood 2000, 96:4028-38.

5. Gauchat JF, Henchoz S, Mazzei G, Aubry JP, Brunner T, Blasey H, Life $P$, Talabot D, Flores-Romo L, Thompson J: Induction of human IgE synthesis in B cells by mast cells and basophils. Nature 1993, 365:340-43.

6. Kasaian MT, Clay MJ, Happ MP, Garman RD, Hirani S, Luqman M: IL4 production by allergen-stimulated primary cultures: Identification of basophils as the major IL-4 producing cell type. Int Immunol 1996, 8: 1287-97.

7. Devouassoux G, Forster B, Scott LM, Metcalfe DD, Prussin C: Frequency and characterization of antigen-specific IL-4 and IL13 producing basophils and Tcells in peripheral blood of healthy and asmathic subjects. J Allergy Clin Immunol 1999, 104:8I I-19.

8. Galli SJ: Mast cells and basophils. Curr Opin Hematol 2000, 7:32-9.

9. Gane P, Pecquet C, Lamblin P, Abuaf N, Leynadier F, Rouger P: Flow cytometric evaluation of human basophils. Cytometry 1993, 14:344-8.

10. Demoly P, Lebel B, Messaad D, Sahla H, Rongier M, Daures JP, Godard $P$, Bousquet J: Predictive capacity of histamine release for the diagnosis of drug allergy. Allergy 1999, 54:500-6.

II. Sainte-Laudy J, Sabbah A, Vallon C, Guerin JC: Analysis of anti-IgE and allergen induced human basophil activation by flow Cytometry. Comparison with histamine release. Inflamm Res 1998, 47:40I-8.

12. Abuaf N, Rajoely B, Ghazouani E, Levy DA, Pecquet C, Chabane H, Leynadier $\mathrm{F}$ : Validation of a flow cytometric assay detecting in vitro basophil activation for the diagnosis of muscle relaxant allergy. J Allergy Clin Immunol 1999, 104:4I I-8.

13. Monneret G, Gutowski MC, Bienvenu J: Detection of allergeninduced basophil activation by expression of CD63 antigen using flow cytometric method. Clin Exp Immunol 1999, I I5:393-6.

14. Gane P, Pecquet C, Crespeau H, Lambin P, Leynadier F, Rouger P. Flow cytometric monitoring of allergen induced basophil activation. Cytometry 1995, 19:361-365.

15. Knol EF, Mul FP, Jansen H, Calafat J, Roos D: Monitoring human basophil activation via CD63 monoclonal antibody 435 . J Allergy Clin Immunol 199I, 88:328-38.

16. Fureder W, Agis $H$, Sperr WR, Lechner K, Valent P: The surface membrane antigen phenotype of human blood basophils. Allergy 1994, 49:861-5.

17. Pâris-Köhler A, Demoly P, Persi L, Lebel B, Bousquet J, Arnoux B: In vitro diagnosis of cypress pollen allergy by using cytofluorimetric analysis of basophils (Basotest). J Allergy Clin Immunol 2000, 105:339-45.

18. Sainte-Laudy J, Sabbah A, Drouet M, Lauret MG, Loiry M: Diagnosis of venom allergy by flow cytometry. Correlation with clinical history, skin tests, specific IgE, Histamine and Leukotriene C4 release. Clin Exp Allergy 2000, 30: I I 66-7I.

19. Sanz ML, Sanchez G, Gamboa PM, Vila L, Uasuf C, Chazot M, Dieguez I, De Weck AL: Allergen-induced basophil activation: CD63 cell expression deteced by flow cytometry in patients allergic to Dermatophagoides pteronyssinus and Lolium perenne. Clin Exp Allergy 200I, 31:1007-13.

20. Saporta M, Kamei S, Persi L, Bousquet J, Arnoux B: Basophil activation during pollen season in patients monosensitized to grass pollen. Allergy 200I, 56:442-5.

21. Ebo DG, Hagendorens MM, Bridts $\mathrm{CH}$, Schuerwegh AJ, De Clerck LS Stevens WJ: In vitro allergy diagnosis: should we follow the flow? Clin Exp Allergy 2004, 34:332-339.

22. Torres MJ, Padial A, Mayorga C, Fernandez T, Sanchez-Sabate E, Cornejo-Garcia JA, Antunez C, Blanca M: The diagnostic interpretation of basophil activation test in immediate allergic reactions to betalactams. Clin Exp Allergy 2004, 34: 1768-75.

23. Erdmann SM, Sachs B, Kwiecien R, Moll-Slodowy S, Sauer I, Merk HF: The basophil activation test in wasp venom allergy: sensitiv- 
ity, specificity and monitoring specific immunotherapy. Allergy 2004, 59: I 102-9.

24. Ebo DG, Hagendorens MM, Bridts CH, Schuerwegh AJ, De Clerck LS Stevens W]: Flow cytometric analysis of in vitro activated basophils, specific IgE and skin tests in the diagnosis of pollen-associated food allergy. Cytometry 2005, 64:28-33.

25. Monneret G, Benoit Y, Debard AL, Gutowski MC, Topenot I, Bienvenu J: Monitoring of Basophil activation using CD63 and CCR3 in allergy to muscle relaxant drugs. Clin Immunol 2002, 102:192-9.

26. Sanz ML, Gamboa PM, Antepara I, Uasuf C, Vila L, Garcia-Aviles C, Chazot M, De Weck AL: Flow cytometric basophil activation test by detection of CD63 expression in patients with immediate-type reactions to betalactam antibiotics. Clin Exp Allergy 2002, 32:277-86.

27. Buhring HJ, Simmons PJ, Pudney M, Muller R, Jarrossay D, van Agthoven A, Willheim M, Brugger W, Valent $P$, Kanz L: The monoclonal antibody $97 \mathrm{A6}$ defines a novel surface antigen expressed on human basophils and their multipotent progenitors. Blood 1999, 94:2343-56

28. Buhring HJ, Seiffert M, Giesert C, Marxer A, Kanz L, Valent P, Sano K: The basophil activation marker defined by antibody $97 \mathrm{A6}$ is identical to the ectonucleotide pyrophosphatase/phosphodiesterase 3. Blood 200I, 97:3303-5.

29. Bollen M, Gijbers R, Ceulemans H, Stalmans W, Stefan C: Nucleotide pyrophosphatase/phophodiesterases on the move. Crit Rev Biochem Mol Biol 2000, 35:393-432.

30. Platz IJ, Binder M, Marxer A, Lischka G, Valent $P$, Bühring $H$ : Hymenoptera-venom-induced upregulation of the basophil activation marker ecto-nucleotide pyrophosphatase/phosphodieterase 3 in sensitized individuals. Int Arch Allergy Immunol 200I, I 26:335-42

31. Hauswirth AW, Natter S, Ghannadan M, Majlesi Y, Schernthaner GH, Sperr WR, Buhring HJ, Valenta R, Valent P: Recombinant allergens promote expression of CD203c on basophils in sensitized individuals. J Allergy Clin Immunol 2002, I I 0: I02-9.

32. Bühring HJ, Streble A, Valent P: The basophil-specific ectoenzyme E-NPP3 (CD203c) as a marker for cell activation and allergy diagnosis. Int Arch Allergy Immunol 2004, I33:3 I7-329.

33. Kahlert $\mathrm{H}$, Cromwell $\mathrm{O}$, Fiebig $\mathrm{H}$ : Measurement of basophil-activating capacity of grass pollen allergens, allergoids and hypoallergenic recombinant derivatives by flow cytometry using anti-CD203c. Clin Exp Allergy 2003, 33:1266-72.

34. Boumiza R, Monneret G, Forissier MF, Savoye J, Gutowski MC, Powell WS, Bienvenu J: Marked improvement of the basophil activation test by detecting CD203c instead of CD63. Clin Exp Allergy 2003, 33:259-265.

35. Kinet JP: The high-affinity IgE receptor (Fc\&RI): From physiology to pathology. Ann Rev Immunol 1999, I7:931-72.

36. Hennersdorf F, Florian S, Jakob A, Baumgartner K, Sonneck K, Nordheim A, Biedermann $T$, Valent $P$, Buhring $H$ J: Identification of CDI3, CDI07a, and CDI64 as novel basophil-activation markers and dissection of two response patterns in time kinetics of ige-dependent upregulation. Cell Res 2005, 1 5:325-35.

37. Monneret G, Boumiza R, Gravel S, Cossette C, Bienvenu J, Rokach J Powell WS: Effects of prostaglandin D2 and 5-lipoxygenase products on the expression of CD203c and CDIIb by basophils. J Pharmacol Exp Ther 2005, 3 | 2:627-34.

38. Cosmi L, Annunziato F, Galli MIG, Maggi RME, Nagata K, Romagnani S: CRTH2 is the most reliable marker for the detection of circulating human type 2 Th and type $2 \mathrm{~T}$ cytotoxic cells in health and disease. Eur J Immunol 2000, 30:2972-2979.

39. Nagata K, Tanaka K, Ogawa K, Kemmotsu K, Imai T, Yoshie O, Abe $H$, Tada K, Nakamura M, Sugamura K, Takano S: Selective expression of a novel surface molecule by human Th2 cells in vivo. J Immunol 1999, 162:1278-1286.

40. Hirai H, Tanaka K, Yoshie O, Ogawa K, Kenmotsu K, Takamori Y, Ichimasa M, Sugamura K, Nakamura M, Takano S, Nagata K: Prostaglandin D2 selectively induces chemotaxis in T helper type 2 cells, eosinophils, and basophils via seven-transmembrane receptor CRTH2. J Exp Med 200I, 193:255-26I.

4I. Monneret G, Gravel S, Diamond M, Rokach J, Powell WS: Prostaglandin D2 is a potent chemoattractant for human eosinophils that acts via a novel DP receptor. Blood 200I, 98:1942-1948.
42. Bouvier G, Debard AL, Gendt L, Canino C, Bienvenu J, Monneret G: A new three-colour flow cytometric combination (CD203C/ CRTH2/CD3) for monitoring allergen-induced basophil activation. Cytometry 2004, 59A: 134

43. Heinemann A, Hartnell A, Stubbs VE, Murakami K, Soler D, LaRosa G, Askenase PW, Williams TJ, Sabroe I: Basophil responses to chemokines are regulated by both sequential and cooperative receptor signalling. J Immunol 2000, 165:7224-7233.
Publish with Biomed Central and every scientist can read your work free of charge

"BioMed Central will be the most significant development for disseminating the results of biomedical research in our lifetime. "

Sir Paul Nurse, Cancer Research UK

Your research papers will be:

- available free of charge to the entire biomedical community

- peer reviewed and published immediately upon acceptance

- cited in PubMed and archived on PubMed Central

- yours - you keep the copyright 